Case Report

\title{
Atypical Distant Metastasis of Breast Malignant Phyllodes Tumors: A Case Report and Literature Review
}

\author{
Tiphaine de Foucher, ${ }^{1}$ Hélène Roussel, ${ }^{2}$ Mikael Hivelin, ${ }^{3,4}$ Léa Rossi, ${ }^{1,4}$ Caroline Cornou, ${ }^{1,4}$ \\ Anne-Sophie Bats, ${ }^{1,4}$ Myriam Deloménie, ${ }^{1}$ Fabrice Lécuru, ${ }^{1,4}$ and Charlotte Ngô ${ }^{1,4}$ \\ ${ }^{1}$ Department of Breast and Gynecological Surgical Oncology, Hôpital Européen Georges Pompidou, AP-HP, Paris, France \\ ${ }^{2}$ Department of Pathology, Hôpital Européen Georges Pompidou, AP-HP, Paris, France \\ ${ }^{3}$ Department of Plastic and Reconstructive Surgery, Hôpital Européen Georges Pompidou, AP-HP, Paris, France \\ ${ }^{4}$ Paris Descartes University, Sorbonne Paris Cité, Paris, France \\ Correspondence should be addressed to Charlotte Ngô; charlotte.ngo@aphp.fr
}

Received 17 May 2017; Accepted 11 September 2017; Published 11 October 2017

Academic Editor: Erich Cosmi

Copyright (C) 2017 Tiphaine de Foucher et al. This is an open access article distributed under the Creative Commons Attribution License, which permits unrestricted use, distribution, and reproduction in any medium, provided the original work is properly cited.

Malignant phyllodes tumors (MPT) are rare breast neoplasms. Preoperative diagnosis is often challenging due to the unspecific clinical, radiological, and histological characteristics of the tumor. Dissemination pathways are local with chest wall invasion, regional with lymph nodes metastasis, and distant, hematogenous, mostly to the lungs, bones, and brain. Distant metastasis (DM) can be synchronous or appear months to years after the diagnosis and initial management. The current report describes the case of a 57-year-old woman presenting with a giant/neglected MPT of the breast, with no DM at initial staging, treated by radical modified mastectomy. Motor disorders due to medullar compression by a paravertebral mass appeared at short follow-up, also treated surgically. The patient died from several DM of rapid evolution. To our knowledge, this is the only case described of MPT with metastases to soft tissue causing medullar compression. We present a literature review on unusual metastatic localizations of MPT.

\section{Introduction}

Phyllodes tumors (PT) are fibroepithelial tumors characterized by a double-layered epithelial component arranged in clefts surrounded by an overgrowing mesenchymal component organized in leaf-like structures. Grading between benign, borderline, or malignant depends on histological criteria: stromal cellularity, cellular pleomorphism, mitotic activity, margin appearance, and stromal distribution [1]. The average annual incidence rate of malignant phyllodes tumors (MPT) is 2.1 per 1 million women [2].

Surgery allowing tumor-free margins $\geq 1 \mathrm{~cm}$ is the first line of treatment [3]. Axillary lymph node dissection is recommended in case of palpable nodes [4]. Radiotherapy and chemotherapy can be options in case of high metastatic risk or recurrence.

Considering all PT, local recurrence (LR) and distant metastases (DM) rates are estimated around $20 \%$ and $3.5 \%$, respectively [5]. Considering MPT, LR occurs in 40\% and DM in $27 \%$ of the cases, mostly to lungs, bones, brain, and liver [6-9]. The estimated 5-, 10-, and 15-year rates of cause-specific survival for women operated for primary nonmetastatic MPT are $91 \%, 89 \%$, and $89 \%$, respectively [3].

We report the case of a woman with an atypical metastasis from a MPT with a rapidly fatal outcome. We present a literature review about unusual localizations of MPT metastasis.

\section{Case Presentation}

A 57-year-old menopausal woman presented herself to our institution with a giant necrotic breast tumor and ipsilateral axillary lymphadenopathy (Figure 1). Radical mastectomy with axillary node dissection and partial pectoral muscle resection was performed. Bulk size was 10,6 × 5,9 × 6,3 inches and it weighted $4.2 \mathrm{~kg}$. The majority of the lesion was composed of a benign PT but a focal area presented a bulging 


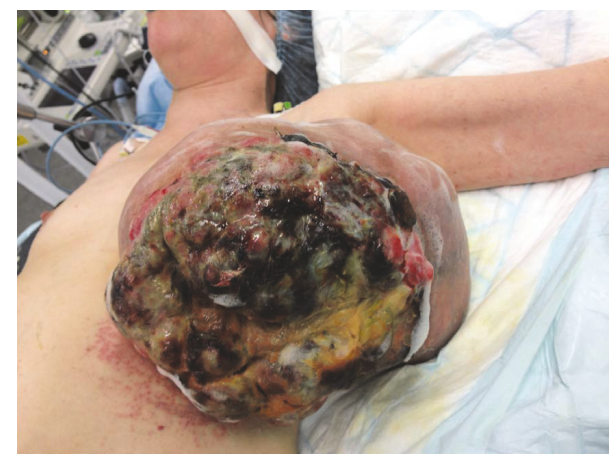

Figure 1: Picture of the left breast mass at diagnosis.

high grade malignant PT with severity criteria: infiltrative borders, high mitotic count, marked stromal overgrowth, and marked stromal cellularity (Figure 2). Axillary lymph nodes were disease-free. Postoperative PET-CT showed no distant metastasis.

Few weeks later, the patient came back with cervical and back pain. She also showed a delirious melancholic episode, successfully treated with neuroleptics.

The spinal MRI revealed several paravertebral lesions: a right paravertebral soft tissue tumor extending from C3 to C5 causing spine displacement and a mass in T11-T12 causing mass effect on the conus medullaris (Figure 3). The occurrence of a cauda equina syndrome indicated an emergency surgery. Histopathological analysis showed a high malignancy tumor proliferation with clusters of spindle shaped cells. The phenotype was unspecific but comparable to the breast tumor (Figure 2).

She then presented multiple and rapidly growing metastasis in soft tissues. Chemotherapy with Adriamycin was initiated but she died rapidly, 4 months after primary diagnosis.

\section{Discussion and Literature Review}

We presented an unusual case of rapidly fatal metastatic evolution of a breast MPT with atypical distant metastasis to paravertebral tissues.

In their retrospective analysis of 295 patients, Mitus et al. found that five-year DFS was $96.9 \%$ in patients with benign PT, $83.3 \%$ in patients with borderline PT, and $71.7 \%$ in patients with malignant PT [7]. 95\% of deaths were related to distant metastasis of malignant PT. The mean survival in case of metastasis was 7 months [range 2-17]. These results are consistent with other articles, which show that metastatic PT carries a poor prognosis, with an average survival time of less than 2 years $[3,6,10]$.

Several grading systems have been proposed, but the three-tiered system including benign, borderline, and malignant PT is preferred [11]. The grading is based on semiquantitative assessment of infiltrative borders, stromal overgrowth, stromal cellularity, stromal pleomorphism, mitotic count ( $\geq 5$ mitoses per $10 \mathrm{HPF}$ ), and the presence of a malignant heterologous component $[9,12,13]$. In our case, in the primary tumor, the histologic criteria of MPT were a high mitotic count with marked stromal overgrowth, high stromal cellularity, and atypia. No malignant heterologous component was found.

The patient waited for more than 18 months before consulting. She demonstrated a strong denial of the disease and of the treatments that were planned. In addition, this patient was in a situation of socioeconomic deprivation. Observing low-income women, Nonzee et al. studied the reasons of delayed breast cancer screening, follow-up, and treatment [14]. They showed that despite equal access to cancer carerelated services, common explanations for nonadherence included limited knowledge about preventive or cancer care resources and denial or fear. Furthermore, it appears that women with locally advanced breast cancer are more likely to suffer from psychiatric comorbidity and more often live alone [15]. In our case, the melancholic episode may have delayed the diagnosis of soft tissue metastases, due to the denial of imaging and medical treatment of the patient. A more effective comanagement of the patient involving both surgeons and psychiatrists might have improved care.

Selection of review of literature for unusual metastasis is summarized in Figure 4. We finally retrieved 17 articles reporting 17 cases. Three patients suffered of cardiac localizations [16-18]. Four patients had gastrointestinal localizations [19-22]. One patient presented with a borderline PT of the right breast and simultaneous pancreatic tail metastasis [23]. Five patients presented with ENT metastasis [24-28]. One patient presented with a thyroid mass two years after a simple mastectomy for a MPT [29]. One case of left kidney metastasis has been reported [30] and one case of adrenal metastasis [31]. The last patient presented with thoracic vertebra and rib metastasis, as well as a pelvic mass [32]. Cases are summarized in Table 1. Mean DFS was 25 months; mean OS was 49 months. 15 patients were dead at the time of publication because of the disease. This highlights the very poor prognosis of patient with unusual DM of MPT.

In case of initially nonmetastatic MPT with high risk of recurrence, adjuvant therapy including radiotherapy and/or different chemotherapeutic agents (ifosfamide, etoposide, doxorubicin, or cisplatin) can be used, although their role is uncertain [4]. Here the rapid apparition of multiple metastases, despite a negative postoperative PET-CT and free surgical margins, raises the question of systematic postoperative radiotherapy and chemotherapy in case of large MPT. In case of distant metastasis, chemotherapy can be used, as well as postoperative radiation therapy as palliation for pain relief, but with limited efficacy [33]. In our case, chemotherapy was quickly started after metastases diagnosis, but the progression of the disease was so fast that the patient died after only one cycle.

Recently, the potential key role of genomic markers in the characterization of PT has been highlighted. MED12 somatic mutations have been identified as a highly recurrent event in fibroadenomas (FAs) and phyllodes tumors (PTs), with an inverse correlation between the frequency of this mutation and histologic grade [34-36]. Laé et al. identified a limited number of altered signaling pathways associated 


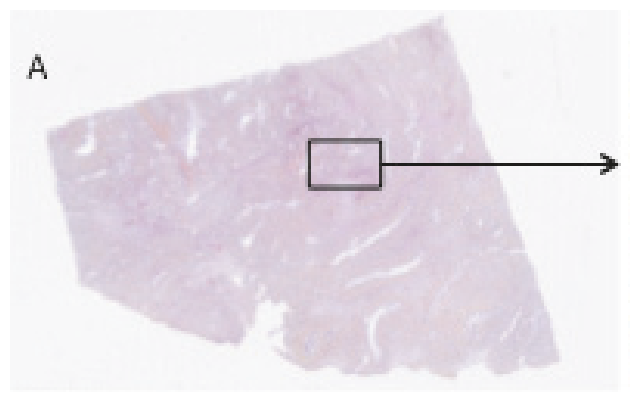

(a)

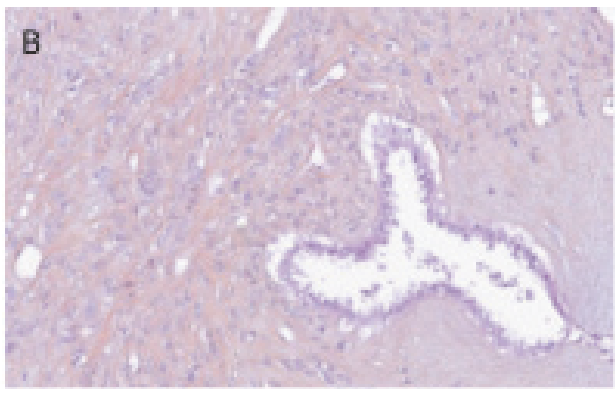

(b)

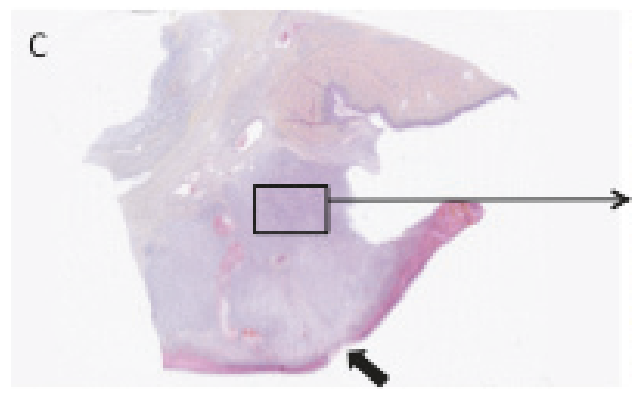

(c)

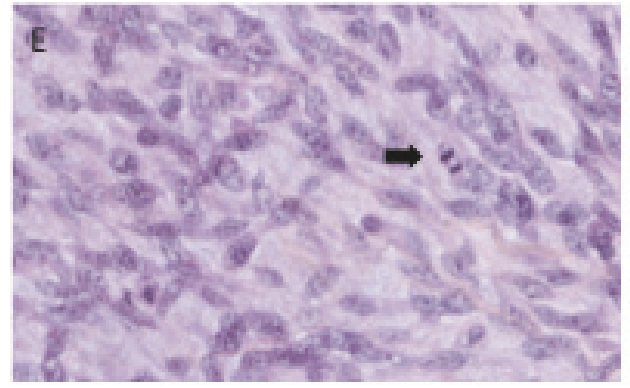

(e)

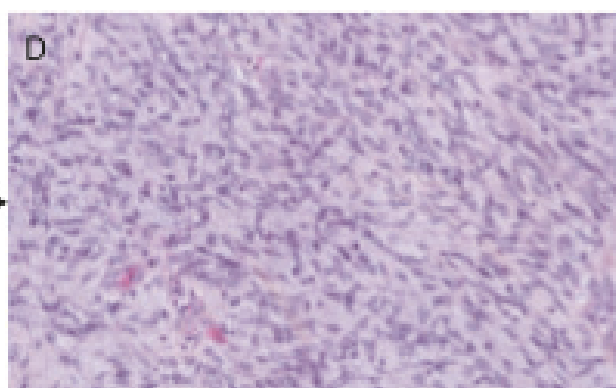

(d)

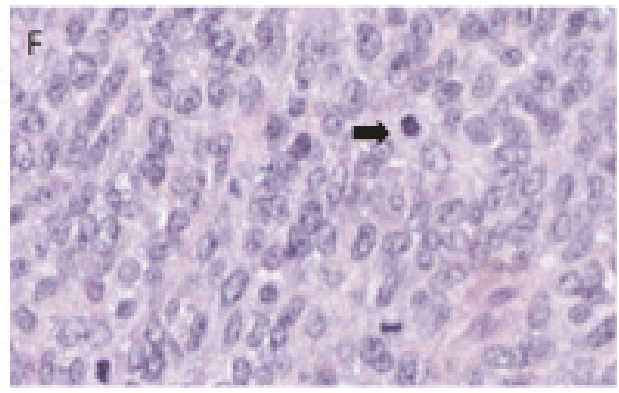

(f)

Figure 2: Microscopic aspect of the primary tumor (a, b, c, d, e) and medullar metastasis (f). (a, b) Predominant benign PT component. The stroma is more cellular than a fibroadenoma. Stromal cellularity may be higher in the zone adjacent to epithelium without atypia and mitosis ( (a) magnification $\times 2$, (b) magnification $\times 200$ ), (c, d) malignant PT component observed near the cutaneous ulceration (arrow). We observed a high stromal cellularity with atypia and mitosis without epithelial structure. There was no involvement of the tissue beneath the nipples nor lymphovascular or neural invasion. ((c) magnification $\times 2$, (d) magnification $\times 200),(e, f)$ malignant primary (e), and medullar metastasis (f) PT at magnification $\times 400$. We observed a similar histologic pattern: a cellular stromal proliferation with atypia and mitosis (arrows). No epithelial components. All immunostainings were negative (estrogen receptor, progesterone receptor, pankeratin AE1, AE3, and PS100, desmin, CD34, caldesmon, and CD99) except for a focal staining with Smooth Muscle Actin antibody.

with this mutation, suggesting the use of these findings as diagnostic and prognostic tools [37]. Focusing on MPT, other authors used molecular profiling to identify overexpressed biomarkers of angiogenesis, EGFR, and immune checkpoints, which points the way toward the use of new targeted therapies [38].

MPT are uncommon breast neoplasm, whose prognosis can be very poor in case of DM. Medullar compression due to soft tissue metastasis is extremely rare. This strengthens the value of an accurate initial diagnosis, so as to enable the identification of high-risk patients. Their management, including monitoring and treatment, is yet to be determined, as the efficiency of treatments used for DM is still low.

\section{Consent}

Consent for publication was obtained from the husband of the deceased patient.

\section{Conflicts of Interest}

The authors have no conflicts of interest to disclose and no funding to declare related to this manuscript. 


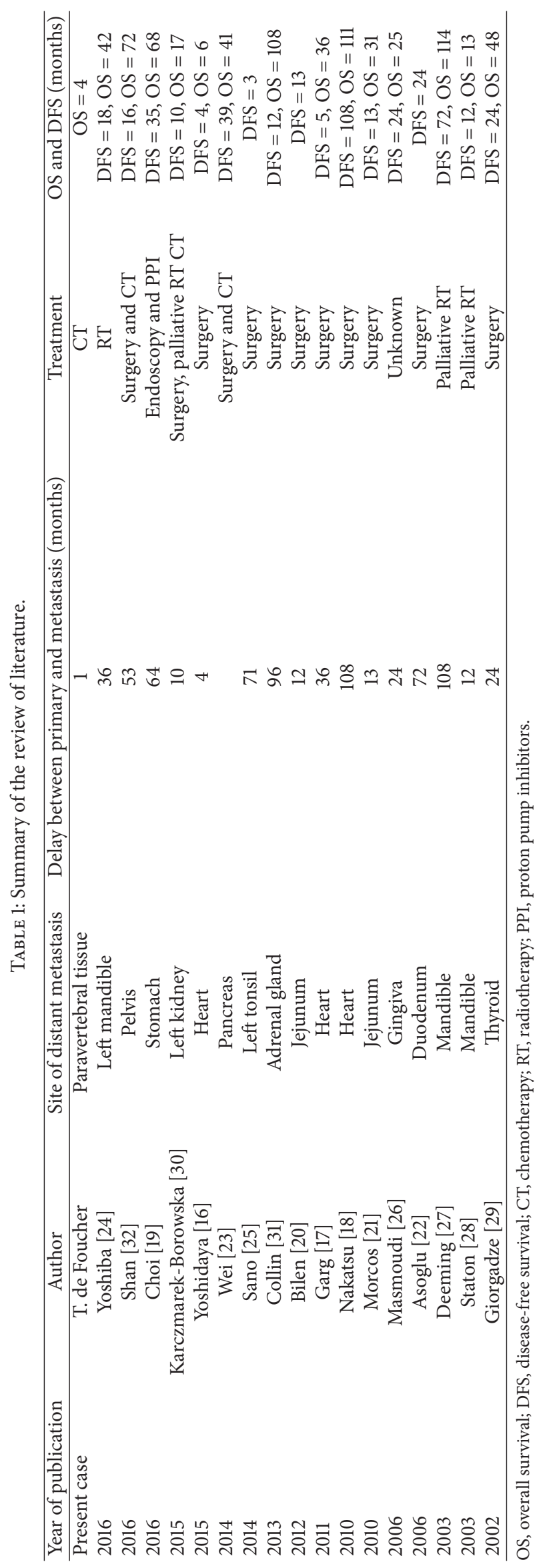




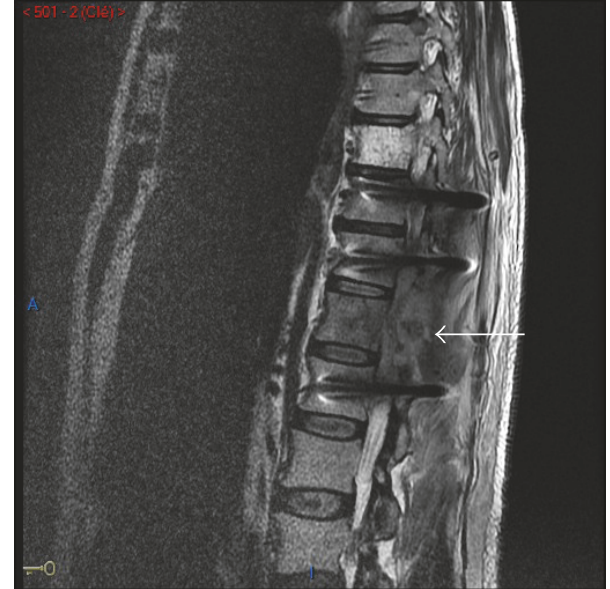

FIGURE 3: Spinal MRI revealing paravertebral lesions between T11T12 causing significant mass effect on the conus medullaris.

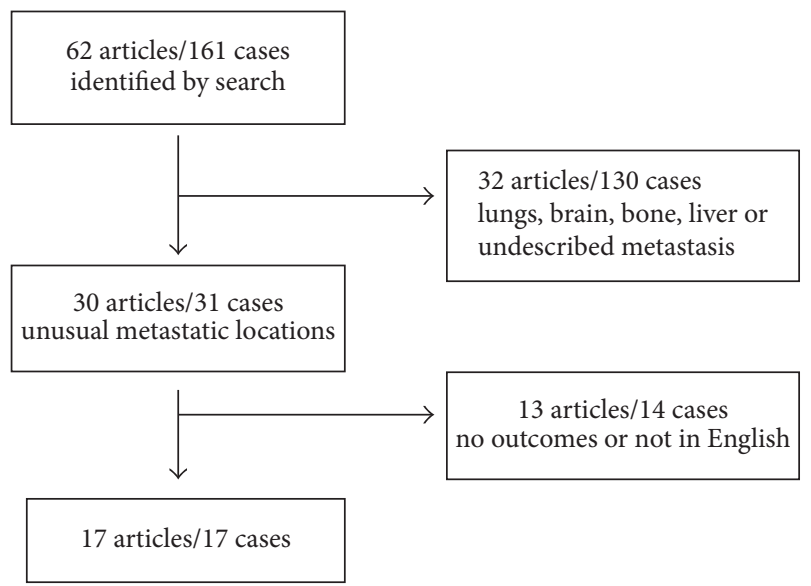

FIGURE 4: Selection for review of literature: references were obtained from the PubMed database, using the keywords "phyllodes tumor metastasis".

\section{Acknowledgments}

The authors thank Mr. Matthew Selwyn for his English grammar corrections.

\section{References}

[1] F. A. Tavassoli, Pathology and genetics of tumours of the breast and female genital organs, World Health Organization Classification of Tumors, 2003, http://www.iarc.fr/en/ publications/pdfd-online/pat-gen/bb4/bb4-chap1.pdf.

[2] L. Bernstein, D. Deapen, and R. K. Ross, "The descriptive epidemiology of malignant cystosarcoma phyllodes tumors of the breast," Cancer, vol. 71, no. 10, pp. 3020-3024, 1993.

[3] O. K. Macdonald, C. M. Lee, J. D. Tward, C. D. Chappel, and D. K. Gaffney, "Malignant phyllodes tumor of the female breast: association of primary therapy with cause-specific survival from the surveillance, epidemiology, and end results (SEER) program," Cancer, vol. 107, no. 9, pp. 2127-2133, 2006.
[4] P. Khosravi-Shahi, "Management of non metastatic phyllodes tumors of the breast: Review of the literature," Surgical Oncology, vol. 20, no. 4, pp. e143-e148, 2011.

[5] Y. Belkacémi, G. Bousquet, and H. Marsiglia, "Phyllodes tumor of the breast," International Journal of Radiation Oncology, Biology and Physics, vol. 70, no. 2, pp. 492-500, 2008.

[6] I. Kapiris, N. Nasiri, R. A’Hern, V. Healy, and G. P. H. Gui, "Outcome and predictive factors of local recurrence and distant metastases following primary surgical treatment of high-grade malignant phyllodes tumours of the breast," European Journal of Surgical Oncology, vol. 27, no. 8, pp. 723-730, 2001.

[7] J. W. Mitus, P. Blecharz, T. Walasek, M. Reinfuss, J. Jakubowicz, and J. Kulpa, "Treatment of patients with distant metastases from phyllodes tumor of the breast," World Journal of Surgery, vol. 40, no. 2, pp. 323-328, 2016.

[8] S. Kim, J.-Y. Kim, D. H. Kim, W. H. Jung, and J. S. Koo, "Analysis of phyllodes tumor recurrence according to the histologic grade," Breast Cancer Research and Treatment, vol. 141, no. 3, pp. 353-363, 2013.

[9] M. Reinfuss, J. Mituś, K. Duda, A. Stelmach, J. Ryś, and K. Smolak, "The treatment and prognosis of patients with phyllodes tumor of the breast: An analysis of 170 cases," Cancer, vol. 77, no. 5, pp. 910-916, 1996.

[10] J. Mitus, M. Reinfuss, and J. W. Mitus, "Malignant phyllodes tumor of the breast: treatment and prognosis," The Breast Journal, vol. 20, no. 6, pp. 639-644, 2014.

[11] S. Lakhani, I. Ellis, and S. Schnitt, WHO classification of tumours of the breast, IARC Press, Lyon, 4th edition, 2012.

[12] A. V. Barrio, B. D. Clark, J. I. Goldberg et al., "Clinicopathologic features and long-term outcomes of 293 phyllodes tumors of the breast," Annals of Surgical Oncology, vol. 14, no. 10, pp. 29612970, 2007.

[13] G. Cohn-Cedermark, L. E. Rutqvist, I. Rosendahl, and C. Silfverswärd, "Prognostic factors in cystosarcoma phyllodes. A clinicopathologic study of 77 patients," Cancer, vol. 68, no. 9, pp. 2017-2022, 1991.

[14] N. J. Nonzee, D. M. Ragas, T. Ha Luu et al., "Delays in cancer care among low-income minorities despite access," Journal of Women's Health, vol. 24, no. 6, pp. 506-514, 2015.

[15] W. A. G. El-Charnoubi, J. B. Svendsen, U. B. Tange, and N. Kroman, "Women with inoperable or locally advanced breast cancer what characterizes them? A retrospective review of 157 cases," Acta Oncologica, vol. 51, no. 8, pp. 1081-1085, 2012.

[16] F. Yoshidaya, N. Hayashi, K. Takahashi et al., "Malignant phyllodes tumor metastasized to the right ventricle: a case report," Surgical Case Reports, vol. 1, no. 1, 2015.

[17] N. Garg, N. Moorthy, S. K. Agrawal, S. Pandey, and N. Kumari, "Delayed cardiac metastasis from phyllodes breast tumor resenting as cardiogenic shock," Texas Heart Institute Journal, vol. 38, no. 4, pp. 441-444, 2011.

[18] T. Nakatsu, T. Koshiji, Y. Sakakibara et al., "Pulmonary artery obstruction due to a metastatic malignant phyllodes tumor of the breast," General Thoracic and Cardiovascular Surgery, vol. 58, no. 8, pp. 423-426, 2010.

[19] D. I. Choi, H. S. Chi, S. H. Lee et al., "A rare case of phyllodes tumor metastasis to the stomach presenting as anemia," Cancer Research and Treatment, vol. 49, no. 3, pp. 846-849, 2016.

[20] M. A. Bilen, R. Laucirica, M. F. Rimawi, J. R. Nangia, and G. S. Cyprus, "Jejunal intussusception due to malignant phyllodes tumor of the breast," Clinical Breast Cancer, vol. 12, no. 3, pp. 219-221, 2012. 
[21] B. B. Morcos, B. Baker, and S. A. Hashem, "Ileocaecal intussusception secondary to metastatic phyllodes tumour of the breast," Annals of the Royal College of Surgeons of England, vol. 92, no. 6, pp. W29-W30, 2010.

[22] O. Asoglu, H. Karanlik, U. Barbaros et al., "Malignant phyllode tumor metastatic to the duodenum," World Journal of Gastroenterology, vol. 12, no. 10, pp. 1649-1651, 2006.

[23] J. Wei, Y.-T. Tan, Y.-C. Cai et al., "Predictive factors for the local recurrence and distant metastasis of phyllodes tumors of the breast: A retrospective analysis of 192 cases at a single center," Chinese Journal of Cancer, vol. 33, no. 10, pp. 492-500, 2014.

[24] S. Yoshiba, T. Saotome, T. Mikogami, and T. Shirota, "Metastasis of mammary gland malignant phyllodes tumor to the mandibular region: a case report and review of the literature," Journal of Oral and Maxillofacial Surgery, 2016.

[25] R. Sano, E. Sato, T. Watanabe et al., "Phyllodes tumor metastasis to the tonsil with synchronous undifferentiated carcinoma," International Journal of Surgery Case Reports, vol. 5, no. 6, pp. 290-293, 2014.

[26] A. Masmoudi, L. Ayadi, and S. Bouassida, "Gingival metastasis in breast phyllodes tumor," Ann Dermatol Venereol, vol. 133, no. 5, pp. 449-451, 2006.

[27] G. Deeming, R. Divakaran, D. Butterworth, and M. Foster, "Temporomandibular region metastasis from cystosarcoma phyllodes: a case report and review of the literature," Journal of Cranio-Maxillo-Facial Surgery, vol. 31, no. 5, pp. 325-328, 2003.

[28] J. B. Staton, T. H. Costello, F. D. Donovan, and R. E. Laster, "Cystosarcoma phyllodes metastatic to the mandible: report of a rare case and literature review," Ear, Nose and Throat Journal, vol. 82, no. 5, pp. 380-381, 2003.

[29] T. Giorgadze, R. M. Ward, Z. W. Baloch, and V. A. LiVolsi, "Phyllodes tumor metastatic to thyroid Hurthle cell adenoma," Arch Pathol Lab Med, vol. 126, no. 10, p. 1233, 2002.

[30] B. Karczmarek-Borowska, A. Bukala, K. Syrek-Kaplita, M. Ksiazek, J. Filipowska, and M. Gradalska-Lampart, "A rare case of breast malignant phyllodes tumor with metastases to the kidney," Medicine (United States), vol. 94, no. 33, p. e1312, 2015.

[31] Y. Collin, F. Chagnon, C. J. Mongeau, G. L. Gonzalez-Amaya, and L. Sideris, "Adrenal metastasis of a phyllodes tumor of the breast: case report and review of the literature," International Journal of Surgery Case Reports, vol. 4, no. 8, pp. 687-689, 2013.

[32] J. Shan, S. Zhang, Z. Wang, Y. Fu, L. Li, and X. Wang, "Breast malignant phyllodes tumor with rare pelvic metastases and long-term overall survival: a case report and literature review," Medicine (Baltimore), vol. 95, no. 38, Article ID e4942, p. e4942, 2016.

[33] D. L. F. Jardim, A. Conley, and V. Subbiah, "Comprehensive characterization of malignant phyllodes tumor by whole genomic and proteomic analysis: Biological implications for targeted therapy opportunities," Orphanet Journal of Rare Diseases, vol. 8, no. 1, article no. 112, 2013.

[34] J. Tan, C. K. Ong, and W. K. Lim, "Genomic landscapes of breast fibroepithelial tumors," Nature Genetics, vol. 47, no. 11, pp. 13411345, 2015.

[35] W. K. Lim, C. K. Ong, J. Tan et al., "Exome sequencing identifies highly recurrent MED12 somatic mutations in breast fibroadenoma," Nature Genetics, vol. 46, no. 8, pp. 877-880, 2014.

[36] N. Yoon, G. E. Bae, S. Y. Kang et al., "Frequency of MED12 mutations in phyllodes tumors: Inverse correlation with histologic grade," Genes, Chromosomes and Cancer, vol. 55, no. 6, pp. 495504, 2016.
[37] M. Laé, S. Gardrat, S. Rondeau et al., "MED12 mutations in breast phyllodes tumors: Evidence of temporal tumoral heterogeneity and identification of associated critical signaling pathways," Oncotarget , vol. 7, no. 51, pp. 84428-84438, 2016.

[38] Z. Gatalica, S. Vranic, A. Ghazalpour et al., "Multiplatform molecular profiling identifies potentially targetable biomarkers in malignant phyllodes tumors of the breast," Oncotarget, vol. 7, no. 2, pp. 1707-1716, 2016. 


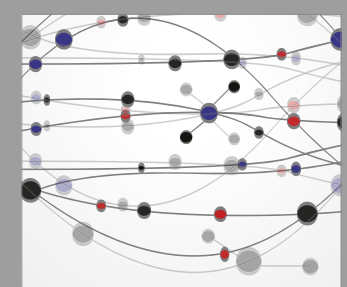

The Scientific World Journal
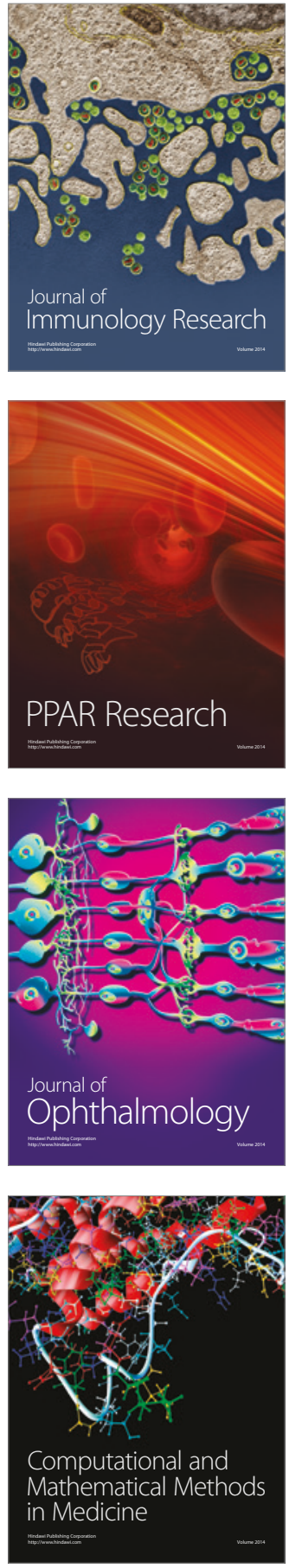

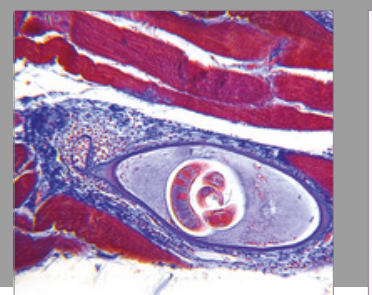

Gastroenterology Research and Practice
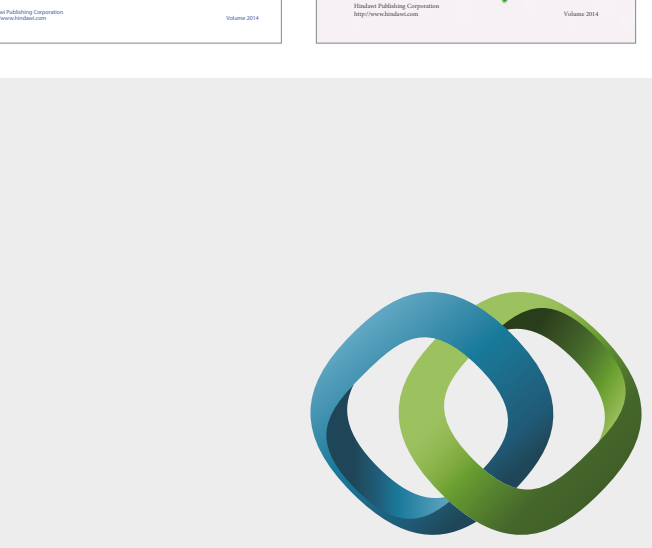

\section{Hindawi}

Submit your manuscripts at

https://www.hindawi.com
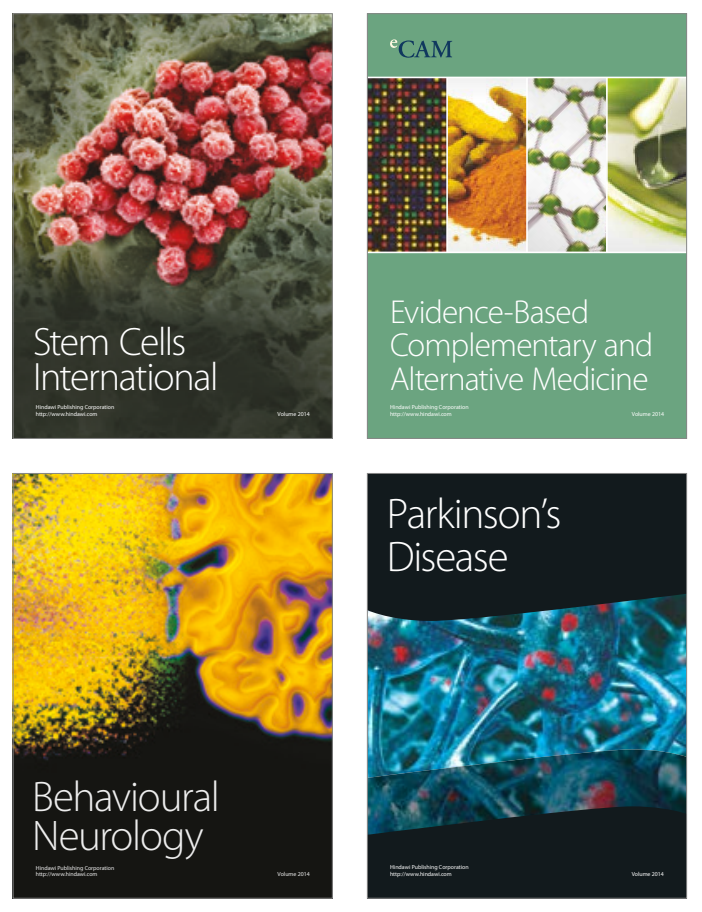
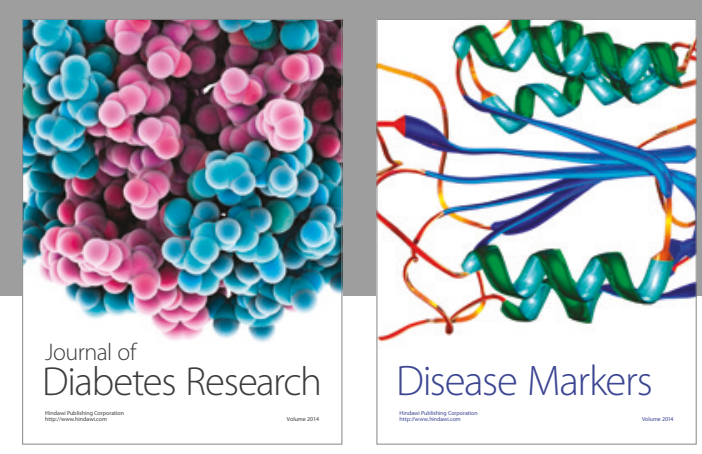

Disease Markers
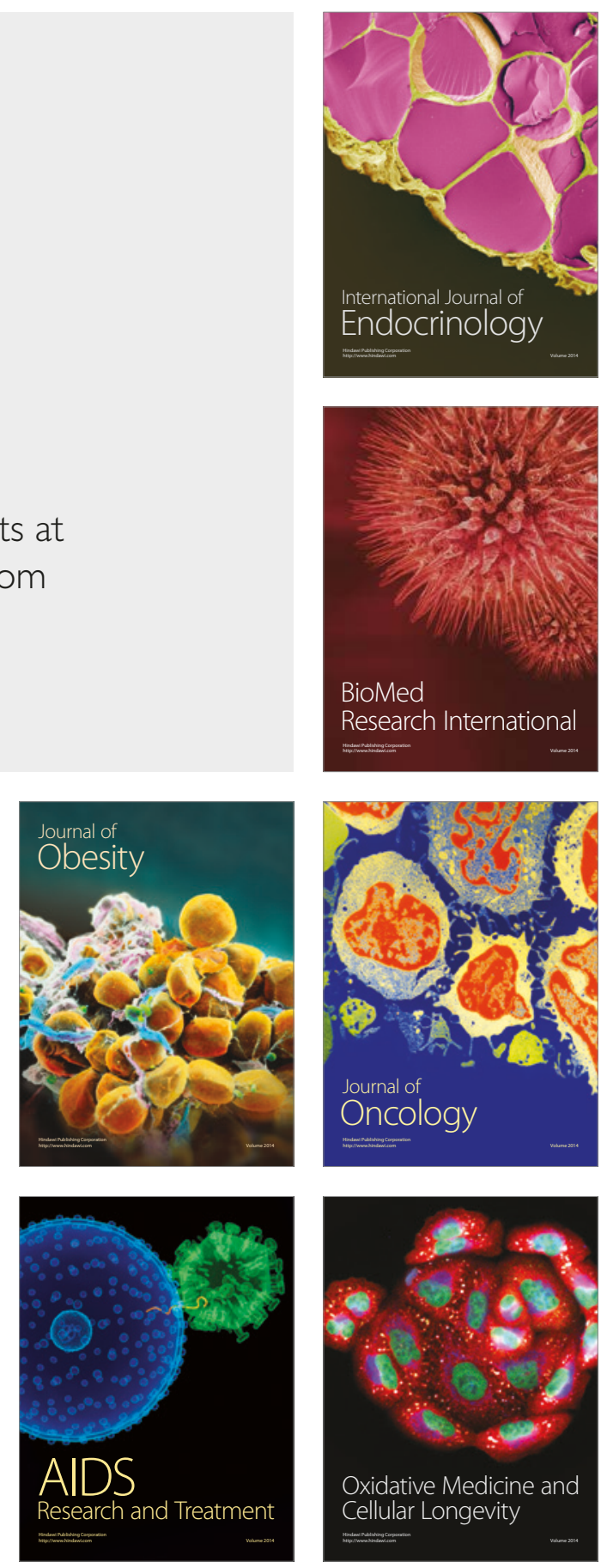